\title{
Glafenine-associated anaphylaxis as a cause of hospital admission in The Netherlands
}

\author{
B.H.Ch.Stricker ${ }^{1,3}$, R.R.M.de Groot ${ }^{2}$, and J.H.P. Wilson ${ }^{1}$ \\ ${ }^{1}$ Department of Internal Medicine II, University Hospital Dijkzigt, Rotterdam, \\ ${ }^{2}$ Dutch Centre for Health Care Information, Utrecht and \\ ${ }^{3}$ Netherlands Centre for Monitoring of Adverse Reactions to Drugs, Rijswijk, The Netherlands
}

Received: July 10, 1990/Accepted in revised form: October 6, 1990

Summary. In 1981 generalized anaphylaxis was registered on 166 occasions in Dutch general and academic hospitals. Clinical details of 120 of those patients revealed that in 107 anaphylaxis was either probable $(\mathrm{n}=90)$ or possible $(n=17)$, whereas in 13 cases some other reaction than anaphylaxis had occurred. The series of confirmed cases contained 46 men and 61 women, with mean ages of $47 y$ and $48 \mathrm{y}$, respectively.

There was a complete recovery in 102 patients and two patients died. Hypotension was present in 79 cases (74\%), dyspnoea in 34 cases (32\%) and a skin reaction, mainly urticaria, erythema or angioedema, was mentioned in 62 cases $(58 \%)$ ). Most cases of anaphylaxis were drug-induced $(76 \%)$, the main causes being the analgesic glafenine and contrast media. Glafenine was mentioned as the cause in $36 \%$ of all admissions for drug-induced anaphylaxis. Only $3.7 \%$ of cases had been reported to the voluntary reporting scheme of the Netherlands Centre for Monitoring of Adverse Reactions to Drugs.

On the basis of reimbursement data, the risk of developing severe anaphylaxis to glafenine was estimated at 11.7-19.3-fold relative to indomethacin, and 13.4-20.2fold relative to oral penicillins.

Key words: Anaphylaxis, glafenine, contrast media; hospital admission, indomethacin, penicillin, adverse reaction monitoring, postmarketing surveillance

Anaphylactic reactions are severe, often life-threatening allergic episodes. The frequency of anaphylaxis during use of drugs is often unknown, but some drugs appear to carry a greater risk of provoking an anaphylactic attack than others. Since the analgesic agent glafenine was introduced on the Dutch market in 1967, it has been the most frequently reported cause of drug-induced anaphylaxis in The Netherlands. Marked and variable underreporting, however, means that such reports cannot be used to assess incidence or relative risk. To estimate the relative risk of severe anaphylaxis to glafenine compared to other drugs, a study has been performed which made use of a central hospital diagnosis system. It showed that glafenine was indeed a major cause of drug-induced anaphylaxis. The willingness of Dutch specialists to provide anonymized clinical details on request, suggests that the methods used might be suitable for other post-marketing surveillance studies.

\section{Material and methods}

The Dutch Centre for Health Care Information is a non-profit organization, which manages 10 nationwide healthcare information systems on its own behalf, or at the request of third parties. One of the systems, a computerized register of hospital diagnoses, files up to 10 diagnoses per patient admission. Registration of the principal diagnosis is obligatory, but the remaining additional diagnoses are filed by the hospital on a voluntary basis. All Dutch general and university hospitals participate in the scheme. The data are confidential and are not used for reimbursement procedures. All diagnoses are coded according to the International Classification of Diseases (ICD-9-CM).

From these data, a separate file was made of all admissions in 1981 in which one or more of the following ICD-diagnoses were registered: 995.0 (anaphylactic shock, including allergic shock, anaphylactic reaction and anaphylaxis), 995.4 (shock due to anaesthesia) and 999.4 (anaphylactic shock due to serum). The specialists involved in the treatment of the patients were sent a request for detailed clinical information and for a copy of the discharge summary.

Each individual case history was analyzed for symptoms, the most likely cause and the probability of it having been an anaphylactic reaction [1]. An anaphylactic reaction was defined as any reaction, which occurred within $1 \mathrm{~h}$ after exposure to any cause, and which consisted of involvement of one or more of the following organ systems:

1. circulatory collapse or hypotension (systolic blood pressure $<100 \mathrm{~mm} \mathrm{Hg}$ ) and symptoms compatible with hypotension

2. respiratory dyspnoea, e.g. due to laryngeal oedema or spasm, bronchospasm

3. skin urticaria, angioedema, erythematous rash

4. gastrointestinal system nausea, vomiting, diarrhoea, urge to defaecate

An anaphylactic reaction was considered "probable" if the symptoms met the criteria defined above, and if the reaction had occurred within $60 \mathrm{~min}$ of dosing or if the temporal relationship was not quantified but was cited as "immediately" or "shortly" after administration. Gastrointestinal symptoms as the only clinical manifestation, 
however, were not classified as anaphylaxis. In cases with circulatory failure as the sole sign or symptom, a case history was only classified as 'anaphylaxis' if cardiac causes had been excluded, and if a vasovagal reaction was considered unlikely. An anaphylactic reaction was considered "possible" if the symptoms were consistent with anaphylaxis, and if the reaction occurred within $120 \mathrm{~min}$. An anaphylactic reaction was considered as "severe" if it was generalized or potentially life-threatening. No distinction was made between anaphylactic and anaphylactoid reactions.

In those cases in which a drug was the most likely cause, a check was made of whether they had been reported to the national adverse reaction monitoring centre. This was done by comparison both of the date of birth of the otherwise anonymized patient and the date of onset of the reaction.

Based on these admission figures, an estimate was made of the relative risk of developing severe anaphylaxis to glafenine $(G)$ as compared to indomethacin (I), to nitrofurantoin $(\mathrm{N})$ and to oral penicillins (OP). In 1981 the marketed oral penicillins were amoxycillin, ampicillin, bacampicillin, carindacillin, cloxacillin, dicloxacillin, phenethicillin, phenoxymethylpenicillin, flucloxacillin, and pivmecillinam. The relative risk was estimated by dividing the ratio of the numbers of admissions attributed to glafenine and to indomethacin $[\operatorname{Adm}(\mathrm{G} / \mathrm{I})]$, nitrofurantoin $[\operatorname{Adm}(\mathrm{G} / \mathrm{N})]$ and penicillins $[\mathrm{Adm}(\mathrm{G} / \mathrm{OP})]$ to the ratio of the reimbursement figures of these drugs $[\operatorname{Reimb}(\mathrm{G} / \mathrm{I}), \operatorname{Reimb}(\mathrm{G} / \mathrm{N})$ and $\operatorname{Reimb}(\mathrm{G} / \mathrm{OP})]$. The resulting relative risk estimates were $\operatorname{Adm}(G / I) / \operatorname{Reimb}(G / I)$, $\operatorname{Adm}(G / N) / \operatorname{Reimb}(G / N)$ and $A d m(G / O P) / \operatorname{Reimb}(G / O P)$, respectively. The reimbursement data were obtained from the Association of Social Health Insurance Funds in The Netherlands, which has a file of drug reimbursement data, based on $71 \%$ of the actual reimbursement figures. A calculation was made of the $95 \%$ confidence intervals of the relative risk by the test-based method [2].

\section{Results}

The file comprised 166 recorded admissions in 1981. The code 995.0 was used 152 times in Dutch hospitals, either as the principal diagnosis $(n=115)$ or as an additional diagnosis $(n=37)$. Code 995.4 was filed 13 times as the principal $(n=3)$ or as an additional diagnosis $(n=10)$, and code 999.4 was registered once (as the principal diagnosis). To the request for clinical details, a response was received for 136 cases $(82 \%)$. In one instance, the specialist refused to give details; in 8 cases the medical records could not be found; in two cases, the episode of anaphylaxis had occurred in 1980; and in another case, one person had been admitted twice. In four cases the information obtained was too scanty to be analysed. All these cases were excluded from the analysis.

In the remaining 120 cases anaphylaxis was regarded as 'probable' in 90 cases, 'possible' in 17 cases, and 'unlikely' in 13 cases. In the latter group only 6 cases had been misclassified; seven patients had developed shock during anaesthesia (code 995.4) and this is not necessarily an anaphylactic reaction.

The 107 likely (probable and possible) cases of anaphylaxis involved 46 men and 61 women, with mean ages of $47 \mathrm{y}$ (range 4-80y; SD 17.6) and $48 \mathrm{y}$ (range 9-80y; SD 19.2), respectively. In 56 cases $(52.3 \%)$ anaphylaxis was the reason for admission, and 46 patients ( $43 \%$ ) had developed the reaction to a procedure during admission $(n=22)$ or in the outpatient department $(n=24)$. This information was not available for 5 patients. The reaction was severe (as defined above) in all 107 patients. Re- covery was complete in 102 patients, 2 patients died (1 attributed to dextran and 1 to contrast medium), and in 3 cases the outcome was not clearly stated. The large majority of patients had been treated, mainly by intravenous or subcutaneous administration of adrenaline and with corticosteroids.

The following symptoms were mentioned in the discharge summaries: shock or moderate hypotension were present in $79(74 \%)$, and absent from $13(12 \%)$ patients; dyspnoea was observed in 34 (32\%), and was absent from $39(36 \%)$ patients; a skin reaction was noted in $62(58 \%)$, and was absent from $16(15 \%)$ patients. Gastrointestinal symptoms had been present in $25 \%$ of patients.

A frequency table shows that drugs were the most important cause of anaphylaxis occurring in hospital or as a reason for admission (Table 1 ). Of the 82 patients with a drug-induced cause listed in this table, $31(38 \%)$ had used the drug before, whereas 2 patients had used the suspected agent for the first time. In the remaining 49 cases $(60 \%)$, this was not clearly stated. Eleven of the $82 \mathrm{pa}-$ tients had a similar, but usually milder reaction previously. The most frequently reported causes were glafenine and contrast media (Table 2). For obvious reasons, most instances of anaphylaxis to contrast media occurred during hospital admissions or out-patient procedures. A separate analysis of all cases of anaphylaxis as a reason for admission from outside hospitals showed that glafenine was implicated in $21 \%$ of all admissions, and that it accounted for $34 \%$ of all drug-induced causes (Table 3 ). A separate analysis of all 'probable' cases did not change this percentage.

An estimate of the risk of developing anaphylaxis (as a reason for admission), relative to indomethacin, nitrofurantoin and oral penicillins derived from the main causes in Table 3, is shown in Table 4. The ratios of the reimbur-

Table 1. Causes of anaphylaxis which occurred during admission, or which were the reason for admission to hospital

\begin{tabular}{|c|c|}
\hline Cause & number $(\%)$ \\
\hline Drugs & $82(76 \%)$ \\
\hline Food & $6(6 \%)$ \\
\hline Insects & $(8 \%)$ \\
\hline Other causes ${ }^{\mathrm{a}}$ & $(4 \%)$ \\
\hline Unknown & $(6 \%)$ \\
\hline Total: & $107(100 \%)$ \\
\hline
\end{tabular}

a other causes: exercise $(n=2)$, occupation (dyes; $n=1)$, cats/pollen $(n=1)$

Table 2. Most frequently notified drug-induced causes of anaphylaxis during admission, or as a reason for admission to Dutch hospitals $(1981)^{\mathrm{a}}$

\begin{tabular}{lc}
\hline Drugs & Number (\%) \\
\hline Contrast media & $28(34 \%)$ \\
Glafenine & $14(17 \%)$ \\
Desensitisation allergens & $9(11 \%)$ \\
Propyphenazone & $5(6 \%)$ \\
Dextrans & $4(5 \%)$ \\
Benzylpenicillin & $2(3 \%)$ \\
Nitrofurantoin & $2(3 \%)$ \\
\hline
\end{tabular}

a Only causes which were noted more than once 
Table 3. Causes of anaphylaxis as a reason for admission in $1981^{\text {a }}$

\begin{tabular}{|c|c|c|}
\hline Causes & Total number $(\%)$ & $\begin{array}{l}\text { Drug-induced } \\
\text { causes }(\%)\end{array}$ \\
\hline $\begin{array}{l}\text { Food } \\
\text { Insects } \\
\text { Other causes } \\
\text { Unknown }\end{array}$ & $\begin{array}{lr}6 & (10.6 \%) \\
9 & (16.1 \%) \\
3 & (5.4 \%) \\
3 & (5.4 \%)\end{array}$ & \\
\hline $\begin{array}{l}\text { Glafenine } \\
\text { Desensitisation allergens } \\
\text { Propyphenazone } \\
\text { Nitrofurantoin } \\
\text { Acetylsalicylic acid } \\
\text { Nalidixic acid } \\
\text { Corticotropin } \\
\text { Tetracosactide } \\
\text { Phenethicillin } \\
\text { Indomethacin } \\
\text { Oxyphenbutazone } \\
\text { Antihistamines }\end{array}$ & $\begin{array}{rr}12 & (21.4 \%) \\
7 & (12.5 \%) \\
5 & (8.8 \%) \\
2 & (3.6 \%) \\
2 & (3.6 \%) \\
1 & (1.8 \%) \\
1 & (1.8 \%) \\
1 & (1.8 \%) \\
1 & (1.8 \%) \\
1 & (1.8 \%) \\
1 & (1.8 \%) \\
1 & (1.8 \%)\end{array}$ & $\begin{array}{r}34.3 \% \\
20.0 \% \\
14.3 \% \\
5.8 \% \\
5.8 \% \\
2.8 \% \\
2.8 \% \\
2.8 \% \\
2.8 \% \\
2.8 \% \\
2.8 \% \\
2.8 \%\end{array}$ \\
\hline Total & $56(100 \%)$ & $100 \%$ \\
\hline
\end{tabular}

a Anaphylaxis during admission, or during procedures in the outpatient department are excluded

sement figures, which were used as the denominators in the relative risk estimates, are also shown. No comparison was made with the other drugs in Table 3 because of the risk of confounding by indication, e.g. antihistamines, allergens, corticotropin and tetracosactide; the absence of reimbursement figures for oxyphenbutazone (not registered), acetylsalicylic acid and propyphenazone ('overthe-counter' preparations); and, the low prescription rate of nalidixic acid. It is clear from these figures that glafenine was the most frequently incriminated agent. Al- though Table 4 suggests that nitrofurantoin also appears to be a common cause, it should be noted that in one of the two reported cases there may have been an acute lung reaction rather than anaphylaxis.

Of the 82 cases with a drug-induced cause, $3(3.7 \%)$ had been reported to the national Adverse Reaction Monitoring Centre. 73 cases $(89 \%)$ had not been reported, and information was not available for 6 cases.

\section{Discussion}

The data for 1981 were analysed because it was the most recent year in the period in which anaphylaxis to glafenine was frequently reported and in which the drug was extensively used in The Netherlands. With declining use, a low prevalence of exposure may make it difficult to estimate the relative risk of a rare event like anaphylaxis, and because of its low incidence, prospective cohort studies are not a very useful approach. Although casecontrol studies are very suitable for studying rare events, there were three reasons for not using this type of study. First, it would be difficult to find a control group be prone to the same likelihood of recall bias about an acute event such as anaphylaxis. Second, differential misclassification of exposure in the index and control groups would be a possible cause of bias, because medical practitioners might enquire more insistently about the intake of drugs known to cause anaphylaxis. And third, casecontrol studies are very effective when the association between a rare event and the use of a drug is uncertain. Generalized anaphylaxis, however, is easily recognized because of the clear symptoms and signs, and its tempo-
Table 4. Relative risk estimate of developing anaphylaxis as a reason for hospital admission

\begin{tabular}{|c|c|c|c|}
\hline & Admissions & Reimbursement figures & Relative risk $^{a}$ \\
\hline $\begin{array}{l}\text { glafenine/indomethacin } \\
\text { tablets/capsules } \\
\text { prescriptions }\end{array}$ & $\begin{array}{l}12 / 1: \\
12 / 1:\end{array}$ & $\begin{array}{r}14.3 / 23.1 \times 10^{6}= \\
399 / 389 \times 10^{3}=\end{array}$ & $\begin{array}{l}19.3(4.5-82.3)^{\mathrm{b}} \\
11.7(2.4-58.2)^{\mathrm{b}}\end{array}$ \\
\hline $\begin{array}{l}\text { glafenine/nitrofurantoin } \\
\text { tablets/capsules } \\
\text { prescriptions }\end{array}$ & $\begin{array}{l}12 / 2: \\
12 / 2:\end{array}$ & $\begin{array}{l}14.3 / 7.3 \times 10^{6}= \\
399 / 172 \times 10^{3}=\end{array}$ & $\begin{array}{l}3.1(0.7-12.6) \\
2.6(0.6-10.9)\end{array}$ \\
\hline $\begin{array}{l}\text { glafenine/penicillins } \\
\text { tablets/capsules } \\
\text { prescriptions }\end{array}$ & $\begin{array}{l}12 / 1: \\
12 / 1:\end{array}$ & $\begin{array}{r}14.3 / 16.1 \times 10^{5}= \\
399 / 671 \times 10^{3}=\end{array}$ & $\begin{array}{l}13.4(2.8-64.1)^{\mathrm{b}} \\
20.2(4.8-84.8)^{\mathrm{b}}\end{array}$ \\
\hline $\begin{array}{l}\text { nitrofurantoin/indomethacin } \\
\text { tablets/capsules } \\
\text { prescriptions }\end{array}$ & $\begin{array}{l}2 / 1: \\
2 / 1:\end{array}$ & $\begin{array}{l}7.3 / 23.1 \times 10^{5}= \\
172 / 389 \times 10^{3}=\end{array}$ & $\begin{array}{l}6.3(0.8-51.3) \\
4.5(0.5-40.2)\end{array}$ \\
\hline $\begin{array}{l}\text { nitrofurantoin/penicillins } \\
\text { tablets/capsules } \\
\text { prescriptions }\end{array}$ & $\begin{array}{l}2 / 1: \\
2 / 1:\end{array}$ & $\begin{array}{l}7.3 / 16.1 \times 10^{6}= \\
172 / 671 \times 10^{3}=\end{array}$ & $\begin{array}{l}4.4(0.5-39.5) \\
7.8(1.03-59.1)^{\mathrm{b}}\end{array}$ \\
\hline $\begin{array}{l}\text { penicillins/indomethacin } \\
\text { tablets/capsules } \\
\text { prescriptions }\end{array}$ & $\begin{array}{l}1 / 1: \\
1 / 1:\end{array}$ & $\begin{array}{r}16.1 / 23.1 \times 10^{6}= \\
671 / 389 \times 10^{3}=\end{array}$ & $\begin{array}{l}1.4(0.1-22.6) \\
0.6(0.04-8.9)\end{array}$ \\
\hline $\begin{array}{l}\text { glafenine/all drugs }^{\mathrm{c}} \\
\text { tablets/capsules } \\
\text { prescriptions }\end{array}$ & $\begin{array}{l}12 / 4: \\
12 / 4:\end{array}$ & $\begin{array}{l}14.3 / 46.4 \times 10^{6}= \\
399 / 1232 \times 10^{3}=\end{array}$ & $\begin{array}{l}9.7(3.9-24.4)^{\mathrm{b}} \\
9.3(3.7-23.4)^{\mathrm{b}}\end{array}$ \\
\hline
\end{tabular}

${ }^{a}$ Relative risk $=$ ratio of admissions due to anaphylaxis: ratio of reimbursement figures for index- and control drug (based on tablets/capsules and prescriptions respectively)

b statistically significant: relative risk of unity outside $95 \%$ confidence interval

c Indomethacin, nitrofurantoin and oral penicillins 
ral relationship to exposure, and drugs are a well-known and widely accepted cause of it. Thus, retrospective analysis of all admitted cases of anaphylaxis, by relating the number of cases to reimbursement data, aided estimation of the relative risk. By estimating the risk of anaphylaxis to glafenine relative to other drugs, recall bias is unlikely to have occurred, because all patients experienced the same acute and serious event. The study does have some limitations, however, because of potential misclassification, potential underreporting of diagnoses, and because of the use of reimbursement figures.

By validation of the clinical data, it was possible to distinguish false-positive from true-positive cases. In the study $6 \%$ of the 107 likely cases had undergone false-positive misclassification.

Misclassification may also be negative and false-negative. The former occurs, for instance, when urticaria as the only symptom is rightly classified as 'urticaria' instead of 'anaphylaxis'. False-negative misclassification is less likely but could occur when, for example, anaphylactic shock without a skin reaction but with diarrhoea is classified as gastroenteritis (ICD-code 780.2) and collapse (ICD-code 009.1). The second potential limitation, underreporting, might occur because the registration of additional diagnoses is not mandatory. This could mean that anaphylaxis occurring during admission was not always registered. Underreporting of principal diagnoses, however, does not occur, and all cases of anaphylaxis which lead to admission will have been registered. The third limitation is that reimbursement data are less precise than dispensing or consumption data. Unfortunately, no such data were vailable in 1981.

None of the three above mentioned limitations jeopardized a valid estimate of the relative risk in the present study. False-positive misclassification was substantiated and was low. False-negative misclassification made it impossible to estimate the incidence but not the relative risk, as defined above, because it is as likely to have occurred in both the index (glafenine) and control groups (indomethacin, nitrofurantoin, oral penicillins). There would not have been any underreporting of the principal diagnoses, and since these were the main interest, underreporting did not prevent a valid estimation of the relative risk. Although the data from the health insurance funds are a proxy for consumption by the low and middle socio-economic classes only, it is not known how this might influence the relative risk estimate of anaphylaxis. It must be admitted that the low numbers in the study made the estimate less precise. In our opinion, however, the high relative risk of developing severe anaphylaxis to glafenine, as estimated here, cannot be explained by imprecise figures alone. On the contrary, there are three reasons to believe that the real risk of anaphylaxis to glafenine, relative to penicillins, is higher than was actually estimated in the study. First, the calculations were based only on reimbursement figures of penicillins in tablets or capsules, and not in liquid or intravenous forms. Second, as both prescribing doctors and pharmacists usually explain to patients the importance of completing an antibiotic course in order to prevent the risk of bacterial resistance, it is likely that the number of reimbursed tablets of anti- biotics is a better proxy of the real number of those swallowed, than the number of reimbursed analgesic tablets. And third, the capacity of glafenine to induce anaphylaxis was emphasized in the Dutch medical literature on several occasions in the period prior to 1981 [3-5]. It is not known whether patients with an allergic constitution react more readily to glafenine with anaphylaxis. If so, however, the relative risk might have been underestimated due to selection bias, because there would have been a tendency not to prescribe glafenine to such patients.

Anaphylaxis to glafenine has been documented on several occasions, mostly as descriptive studies of individual cases [3-9]. An estimate of the frequency of the effect has been made, in which sales figures were related to the number of reports following a nationwide enquiry in France concerning this issue. Based on these figures, the frequency was 3.4 cases per 100000 prescriptions [9]. Since the enquiry might have introduced reporting bias, such figures should be interpreted with caution. In the present study reporting bias could not have played a role since the analysis was based on all principal diagnoses from all Dutch hospitals. Because anaphylaxis is easily recognized in most cases, we do not think that bias in recognition distorted the results. There was no significant difference in severity or outcome between anaphylaxis due to glafenine and other causes of admission because of anaphylaxis. Since there are no reports suggesting that glafenine-induced anaphylaxis has a worse prognosis than anaphylaxis induced by other drugs, referral bias appears unlikely.

The incidence of anaphylaxis to penicillins has been estimated at $0.01 \%$ of courses $[10,11]$. Based on the lower margin of the $95 \%$-confidence interval of the point estimate of the relative risk in Table 4, this might mean that glafenine-induced anaphylaxis would have an incidence of approximately 1 case per 2000 courses $(0.05 \%)$. It is emphasized that such extrapolations require cautious interpretation, since the study did not permit direct assessment of the incidence of glafenine-induced anaphylaxis.

In conclusion, it is apparent that the risk of anaphylaxis to glafenine, relative to other drug-induced causes, is high. Although the study was performed in one country, it is likely that the results apply to other countries as well. The risk should be taken into account when deciding whether or not to prescribe this analgesic.

Acknowledgement. We thank Mr. F. Titaley, of the Association of Social Health Insurance Funds, for providing the reimbursement figures of prescriptions in 1981. We also thank Dr. P.H. Dieges, allergologist, for his advice.

\section{References}

1. Wasserman SI, Marquardt DL (1988) Anaphylaxis. In: Allergy. Principles and practice. Middleton E, Reed CE, Ellis EF, Adkinson NF, Yunginger JW (ed) pp 1365-1376

2. Miettinen OS (1976) Estimability and estimation in case-referent studies. Am J Epidemiol 103: 226-235

3. Meyboom RHB (1976) Anafylaxie na het gebruik van glafenine. Ned Tijdschr Geneesk 120: 926-927 
4. Maesen F, Mol JM, Brombacher PJ, Bok EJ, Voorden JMJ, Van de Vijgen JH (1976) Anafylactische shock na gebruik van glafenine (Glifanan). Ned Tijdschr Geneesk 120: 926-927

5. Meyboom RHB (1979) Problemen met glafenine. Geneesmiddelenbull 13:23-26

6. Gaultier M, Bismuth C, Efthymiou ML, Morel-Maroger L, Romion A (1972) Nouv Presse Méd 1: 3125-3128

7. Barral C, Faivre M (1975) Accidents anaphylactiques imputés à la glafenine. Cinq cas. Nouv Presse Méd 4: 2797-2798

8. Michaud JL, Doublet L (1976) Choc induit par la glafénine. Six nouveau cas. Nouv Presse Méd 5: 716

9. Cheymol G, Biour M, Bruneel M, Albengres E, Hamel JD (1985) Bilan d'un enquête nationale prospective sur les effects indésirables de la glafénine, de l'antrafénine et de la floctafénine. Therapie 40: 45-50
10. Saxon A, Beall GN, Rohr AS, Adelman DC (1978) Immediate hypersensitivity reactions to beta-lactam antibiotics. Ann Intern Med 107: 204-215

11. Weiss ME, Adkinson NF (1988) Immediate hypersensitivity reactions to penicillin and related antibiotics. Clin Allergy 18: $515-540$

Dr. B. H. Ch. Stricker

Department of Internal Medicine II

University Hospital Dijkzigt

Dr. Molewaterplein 40

NL-3015 GD Rotterdam

The Netherlands 